Georgia State University

ScholarWorks @ Georgia State University

$12-2016$

\title{
Victimization and microaggressions targeting LGBTQ college students: Gender identity as a moderator of psychological distress
}

\author{
Kristie L. Seelman \\ Georgia State University, kseelman@gsu.edu \\ Michael R. Woodford \\ Wilfrid Laurier University, mwoodford@wlu.ca \\ Z Nicolazzo \\ Northern Illinois University, znicolazzo@niu.edu
}

Follow this and additional works at: https://scholarworks.gsu.edu/ssw_facpub

Part of the Social Work Commons

\section{Recommended Citation}

Seelman, Kristie L.; Woodford, Michael R.; and Nicolazzo, Z, "Victimization and microaggressions targeting LGBTQ college students: Gender identity as a moderator of psychological distress" (2016). SW Publications. 77.

https://scholarworks.gsu.edu/ssw_facpub/77

This Article is brought to you for free and open access by the School of Social Work at ScholarWorks @ Georgia State University. It has been accepted for inclusion in SW Publications by an authorized administrator of ScholarWorks@ Georgia State University. For more information, please contact scholarworks@gsu.edu. 
Running Head: LGBTQ College Students and Psychological Distress

Victimization and Microaggressions Targeting LGBTQ College Students:

Gender Identity as a Moderator of Psychological Distress

\author{
Kristie L. Seelman \\ Georgia State University \\ Michael R. Woodford \\ Wilfrid Laurier University \\ Z Nicolazzo \\ Northern Illinois University
}

The Version of Record of this manuscript has been published and is available in the Journal of

Ethnic \& Cultural Diversity in Social Work, as of December 20, 2016, at

http://www.tandfonline.com/doi/full/10.1080/15313204.2016.1263816

\begin{abstract}
Author Note
Kristie L. Seelman, School of Social Work, Georgia State University, kseelman@gsu.edu; Michael R. Woodford, Lyle S. Hallman Faculty of Social Work, Wilfrid Laurier University, mwoodford@wlu.ca; Z Nicolazzo, Department of Counseling, Adult, and Higher Education, Northern Illinois University, znicolazzo@niu.edu.

We thank the participants, as well as Alex Kulick (PhD student, Department of Sociology, University of California, Santa Barbara), who assisted with the survey and data collection. This study was supported by the National Institute for Institutional Diversity and the Curtis Center, both located at the University of Michigan. It was also supported by Wilfrid Laurier University and the Social Sciences and Humanities Research Council.
\end{abstract}


Correspondence concerning this article should be addressed to Kristie Seelman, School of Social Work, Georgia State University, PO Box 3995, Atlanta, GA 30302-3995. E-mail:

kseelman@gsu.edu 


\begin{abstract}
LGBTQ discrimination continues to be common on college campuses. While a number of studies have examined blatant victimization among students, little attention has been given to LGBTQ microaggressions. In this study, we examine both blatant victimization and microaggressions and their association with psychological distress among LGBTQ college students $(N=497)$ and look at whether gender identity moderates these relationships. Both forms of discrimination are associated with lower self-esteem and greater stress and anxiety. Victimization is more negatively associated with self-esteem among trans* students. Our findings emphasize the importance of addressing both blatant and subtle forms of discrimination targeting LGBTQ college students.
\end{abstract}

Key words: LGBTQ; college students; microaggressions; victimization; campus climate; mental health. 
Despite the increasing visibility of lesbian, gay, bisexual, transgender, queer and questioning (LGBTQ) people, LGBTQ students frequently experience discrimination and a hostile climate on college campuses (Nicolazzo, 2015; Rankin, Weber, Blumenfeld, \& Frazer, 2010; Woodford, Howell, Silverschanz, \& Yu, 2012; Woodford, Kulick, Sinco, \& Hong, 2014). While a growing number of studies have examined blatant victimization among LGBTQ college students and the connection to student well-being, little attention has been given to microaggressions. In the present study, we examine both blatant victimization and microaggressions and their association with psychological distress among LGBTQ college students and look at whether gender identity moderates these relationships.

\section{Experiences of Discrimination Impacting LGBTQ College Students}

Evidence indicates that discrimination is prevalent among the LGBTQ college population at large (Rankin et al., 2010), however recent studies suggest that rates of discrimination are higher for trans ${ }^{* 1}$ individuals than cisgender (non-transgender) students (Dugan, Kusel, \& Simounet, 2012; Rankin et al., 2010). This implies that harassment and discrimination targeting trans* individuals may be more prevalent and less often challenged by others, aligning with overall patterns within university environments in which cisgender identities are treated as the norm and trans* identities are marginalized (Nicolazzo, 2015; Seelman, 2013). Most research examining topics of LGBTQ discrimination and harassment have focused on blatant behaviors (Nadal, 2013), such as physical and sexual assault or threats of violence (e.g., Effrig et al., 2011).

\footnotetext{
${ }^{1}$ We use the term transgender as an umbrella term incorporating anyone whose self-identified gender identity differs from predominant cultural expectations for their sex assigned at birth. This definition incorporates individuals who choose to biomedically transition from one gender to another (i.e., transsexuals), as well as those who elect not to seek such treatment. The shorter term trans* is meant to include a range of non-binary gender identities (e.g., genderqueer) as well as those who may not use the term transgender for themselves.
} 
However, the changing nature of discrimination has meant that more subtle forms of discrimination are often more common (Woodford, Han, Craig, Lim, \& Matney, 2013).

There is a lack of research about LGBTQ college students' experiences of microaggressions (Woodford, Chonody, Kulick, Brennan, \& Renn, 2015). Past studies have documented forms of subtle heterosexist behaviors, including gay jokes and other slurs (Silverschanz, Cortina, Kornik, \& Magley, 2008) and the microaggression "that's so gay" (Woodford et al., 2012). While not always labeled as microaggressions, recent work has documented examples of subtle discrimination affecting trans* people in college, such as facing unreasonable barriers to changing one's name or gender on campus records (Seelman, 2013) and witnessing others minimize the need for changing policies to protect trans* people (Case, Kanenberg, Erich, \& Tittsworth, 2012).

According to the minority stress model (Meyer, 2003), populations that are socially stigmatized face chronic stress due to prejudice and discrimination, which can put them at risk for poor mental health. This model has been usually applied to sexual minorities, including college students (e.g., Woodford et al., 2012; Woodford Kulick, et al, 2014). Several recent studies have used this lens to understand health disparities for trans* individuals (Hendricks \& Testa, 2012; Herman, 2013). Effrig and colleagues (2011) applied this model and found trans* students to be at increased risk for psychological distress compared to their cisgender peers; however, they did not examine the relationship between discrimination and mental health outcomes.

Although subtle manifestations of LGBTQ discrimination are more prevalent on campuses than blatant forms (Rankin et al., 2010), only recently have scholars investigated the former's relationship with students' health. Emerging research indicates that subtle heterosexism 
can have a negative impact on sexual minority college students (Silverschanz et al., 2008;

Woodford et al., 2012; Woodford, Han et al., 2014). In terms of microaggressions, overhearing others use the phrase "that's so gay" as a negative descriptor has been associated with headaches, poor appetite, and feelings of isolation among emerging adult sexual minority students

(Woodford et al., 2012). Further, LGBQ microaggressions were associated with greater psychological distress (anxiety and perceived stress) among LGBQ college students (Woodford, Kulick et al., 2014). In terms of microaggressions targeting trans* individuals, a recent analysis of the National Transgender Discrimination Survey data (using a subsample of participants who ever attended college) found a relationship between being denied access to campus housing or bathrooms - an example of environmental or systemic microaggression — and lifetime suicidality, even after controlling for on-campus victimization by teachers or students (Seelman, 2016). To the best of our knowledge, researchers have not examined microaggressions specifically among current trans* collegians.

\section{The Current Study}

The present study analyzes the relationship between microaggressions and psychological distress (self-esteem, perceived stress, and anxiety) among LGBTQ students. To shed light on the potential differential impacts of blatant and subtle discrimination, we examine both victimization and microaggressions. Moreover, given that research suggests trans* students experience greater discrimination compared to their cisgender peers, we explore gender identity as a moderator between discrimination and distress.

Specifically, we ask: Are experiences of blatant LGBTQ victimization and LGBTQ microaggressions significantly associated with self-esteem, stress, and anxiety among LGBTQ 
college students? And, does gender identity moderate the victimization/microaggression-distress relationship?

\section{Methods}

Data were collected among a convenience sample of self-identified LGBTQ college students who participated in an anonymous, web-based survey $(N=497)$. Participants were recruited via email messages distributed through LGBTQ listservs. To participate, students had to be at least 18 years old, self-identify as LGBTQ, and be current or previous (past year) college students. Participants provided informed consent. The study received approval from the University of Michigan Institutional Review Board.

\section{Participants}

Just under $15 \%(n=72)$ of the sample identified as transgender, genderqueer, or another gender non-conforming identity, while 50\% $(n=244)$ were women and $36 \%(n=177)$ were men. Almost one-third $(29 \%, n=143)$ identified as gay, $20 \%(n=97)$ as lesbian, $18 \%(n=90)$ as queer, $16 \%(n=76)$ as bisexual, $11 \%(n=52)$ as straight/heterosexual, ${ }^{2}$ and $7 \%$ as other $(n=$ 33). Ages ranged from 18 to 61 years, with a median of 24 years. More than three-fourths (79\%, $n=386)$ of the sample was White, and over half $(58 \%, n=289)$ were undergraduate students. A small minority $(8.4 \%, n=42)$ attended schools in Canada. Among participants from the United States, 33 states were represented, with the vast majority of these participants attending schools in the Midwest.

\section{Measures}

\footnotetext{
${ }^{2}$ Some individuals who identified as straight/heterosexual group were trans*. Others, however, were cisgender and reported only heterosexual attraction. When running the multiple linear regression models, we compared final results both with and without this group of 37 cisgender heterosexuals; results were the same either way. Due to the fluid nature of sexuality and gender and the inherent difficult of attaching simple labels to oneself, we chose to retain these respondents in our sample.
} 
LGBTQ discrimination on campus. We inquired about the prevalence of LGBTQ discrimination in terms of threats and insults (blatant victimization) as well as LGBQ/trans* microaggressions within the past year (or since coming to campus, if less than one year; $0=$ Never, 5 = Very frequently). Blatant victimization was evaluated using nine items selected and adapted from earlier measures (D’Augelli, 1992; Herek, 1993) to be inclusive of bisexual, queer, and trans* identities (separate questions were used for sexual orientation and for gender identity, with the victimization act content being parallel across the question sets). We dropped five items focused on the most severe physical attacks and threats due to little variance on these items (most had never experienced such attacks). We retained four items for blatant insults (e.g., "Someone verbally insulted me (e.g., 'f'in tranny') because they knew or assumed I am transgender”) and threats (e.g., "Someone threatened to tell others about my sexual orientation").

Given differences between sexual orientation and trans* microaggressions (Nadal et al., 2010), separate scales were used to assess microaggressions on campus based on each identity. Participants who selected man or woman answered the sexual orientation microaggression items, while those who reported a gender identity of transgender, genderqueer, or other were asked to answer the trans* microaggression questions. These scales capture everyday verbal and nonverbal indignations, insults, and invalidations that occur on college campuses. LGBQ microaggressions were documented using a 20-item measure $(\alpha=.91)$; sample item "I was told I should act 'less lesbian, gay, bisexual, or queer'” (Woodford et al., 2015). Thirty-four items evaluated trans* microaggressions $(\alpha=.92)$; sample item "I was told that I talk about discrimination against transgender or gender queer people too much" (Woodford et al., in progress). 
Psychological distress. We assessed self-esteem, perceived stress, and anxiety. An adapted version of the 10-item Rosenberg Self-Esteem scale was used to measure self-esteem (Rosenberg, 1965). To ensure the measure was accessible and tapped into participants' global self-worth rather than comparative self-concept, we adapted Rosenberg's scale for use among college students by simplifying wording and removing comparisons to others. Self-esteem tends to be unstable in emerging adults (Trzeniewski, Donnellan, \& Robins, 2003); hence, participants were instructed to consider items over the past 12 months on a five-point scale $(1=$ Never true, 5 $=$ Almost always true $; \alpha=.91)$ (Rosenberg, Schooler, Schoenbach, \& Rosenberg, 1995). To measure perceived stress, we used the 10-item Perceived Stress Scale (Cohen, Kamarck, \& Mermelstein, 1983), which captures the degree to which situations in one's life are considered as stressful during the past month $(0=$ Never, $4=$ Very often; $\alpha=.90)$. Anxiety was measured using the GAD-7 scale (Spitzer, Kroenke, Williams, \& Lowe, 2006), which inquires about symptoms of General Anxiety Disorder within the past two weeks $(0=$ Not at all, $3=$ Nearly every day; $\alpha=$ $.89)$.

Socio-demographic variables. Participants reported gender identity, sexual orientation, race, age, student status, and the name of their college (used to determine school location). We assessed gender identity by asking, "How would you describe your current gender identity?" with five options, including Other. This variable was dichotomized (cisgender/trans*) for analysis. Sexual orientation was assessed with, "How would you describe your sexual orientation?" and participants selected from six categories, including Other. Race was originally evaluated using eight categories, which we dichotomized (White/person of color) due to sample size.

\section{Data Analysis}


We used SPSS, version 22, for all analyses. Univariate outliers were detected on the two interaction terms, so we adjusted the values of outliers to be less extreme, though they remained on the tail end of the distribution (Tabachnick \& Fidell, 2007). There were 24 identical multivariate outlier cases across the three models; these cases were significantly more likely to be trans* participants, so we decided to retain these cases, noting that their inclusion may influence models. Several of the independent variables of interest were missing not at random in relation to some of the dependent variables. Tabachnick and Fidell (2007) suggest keeping all cases in such situations due to the bias that can occur when dropping cases that have missing data related to the dependent variables. We therefore chose to use multiple imputation to provide pooled estimates for missing data based on five imputations.

We performed a total of six sequential multiple linear regression models, two for each dependent variable (one including blatant victimization, another including microaggressions). Block 1 included race, gender, and age. Block 2 added the discrimination variable - either victimization or microaggressions. ${ }^{3}$ Block 3 included the interaction terms between gender and the discrimination variable.

\section{Results}

\section{Descriptive Statistics}

The mean score for LGBTQ victimization ( 0.29 , for a scale ranging from 0 to 5$)$ suggests that blatant insults and threats typically occurred between Never and Very Rarely, whereas microaggressions occurred about halfway between Very Rarely and Rarely (mean score of 1.51 on a scale from 0 to 5$)$. For self-esteem, the average score (2.81, on a scale from 1 to 5 ) was

\footnotetext{
${ }^{3}$ We originally ran analyses with victimization and microaggressions in the same models, however these two variables had a moderately strong correlation (.59) that resulted in problems with suppression in the regression models. Therefore, we ran separate regression models for each discrimination variable.
} 
slightly below the scale's midpoint, indicating a moderate degree of self-esteem in the average participant. The mean for perceived stress (1.75, on a scale from 0 to 4 ) was slightly below the scale's midpoint, suggesting overall appraisals of stress were low. The average score on the anxiety measure ( 0.87 , on a scale from 0 to 3 ) suggested that symptoms of anxiety occurred slightly less than Several Days during the past two weeks.

\section{Inferential Statistics}

The results presented here use the pooled data following multiple imputation. However, the Adjusted $R^{2}$ values were computed for the original data since these statistics are not produced for pooled results.

Blatant victimization predicting self-esteem. There was a statistically significant difference between trans* and cisgender individuals in Block 1. The results suggest that trans* participants reported an average self-esteem score that was about 0.19 points lower $(p<.05)$ than that of cisgender participants. Age was also associated with self-esteem: for each year increase in a student's age, self-esteem was predicted to increase by 0.02 points $(p<.01)$. These demographic variables account for about $3 \%$ of the variance in self-esteem scores. In Block 2 , gender is no longer significant, but age remains significantly associated with self-esteem $(\mathrm{B}=$ $0.02, p<.01)$. Experiences of blatant victimization demonstrate a statistically significant negative relationship with self-esteem $(\mathrm{B}=-0.29, p<.001)$. For every one-point increase in victimization, self-esteem is predicted to decrease by 0.29 points. This block accounts for $11 \%$ of the variance in self-esteem scores.

In Block 3, which accounts for $12 \%$ of the variance in self-esteem scores, age remains significantly associated with self-esteem $(\mathrm{B}=0.02, p<.01)$. The cross-product interaction term is also statistically significant (gender $\mathrm{x}$ victimization $\mathrm{B}=-0.91, p<.05$ ), which suggests that the 
effect of victimization on self-esteem depends on one's gender identity. The main effect of victimization $(\mathrm{B}=-0.25, p<.001)$ is the effect among cisgender students, which suggests that victimization has a significant relationship with cisgender students' self-esteem scores so that for each one-point increase in victimization, self-esteem is predicted to decrease by 0.25 points. The coefficient for the interaction term $(\mathrm{B}=-0.91, p<.05)$ is the additional effect of victimization on self-esteem among trans* participants, which suggests that with each one-point increase in victimization, self-esteem is predicted to decrease by 0.91 points. This relationship is also seen in Figure 1. This interpretation of the relationship between victimization and self-esteem by gender identity was also confirmed in post-hoc regression models run separately for cisgender and trans* students (results not reported here).

[Insert Figure 1 approximately here]

Blatant victimization predicting perceived stress. In Block 1 of the model for perceived stress, only age is significantly associated with perceived stress $(\mathrm{B}=-0.02, p<.01)$; demographic variables account for $3 \%$ of the variance in perceived stress scores. For every one year increase in age, stress decreases by 0.02 points. In Block 2 , age remains statistically significant $(\mathrm{B}=-0.02, p<.01)$ and victimization is positively associated with perceived stress $(\mathrm{B}$ $=0.23, p<.001$ ); for each one-point increase in the frequency of victimization, one's stress score is predicted to increase by 0.23 . This block accounts for $7 \%$ of the variance in perceived stress scores. In Block 3 , age $(\mathrm{B}=-0.02, p<.01)$ and victimization $(\mathrm{B}=0.20, p<.01)$ remain statistically significant predictors of perceived stress, but the interaction term (gender $\mathrm{x}$ victimization) is not significant. This final version of the model accounted for $7 \%$ of the variance in perceived stress. 
Blatant victimization predicting anxiety. Age is a marginally significant predictor $(\mathrm{B}=$ $-0.01, p<.10$ ) of anxiety in Block 1 . The demographic variables account for less than $1 \%$ of the variance in student anxiety. In Block 2 , victimization is a significant predictor of anxiety $(\mathrm{B}=$ $0.23, p<.001)$; this block accounts for $6 \%$ of the variance in anxiety. For every one-point increase in victimization, anxiety is predicted to increase by 0.23 points. Victimization remains statistically significant in Block $3(\mathrm{~B}=0.21, p<.001)$, but the interaction term (gender $\mathrm{x}$ victimization) is not significant. This block accounts for $6 \%$ of the variance in anxiety.

Microaggressions predicting self-esteem. For each of the microaggressions models, the results for Block 1 are identical to those in the victimization models, as only the demographics are entered in the first block. In Block 2 of the microaggressions model predicting self-esteem, gender is no longer significant, but age remains significantly associated with self-esteem $(\mathrm{B}=$ $0.02, p<.01)$. LGBTQ microaggressions are negatively associated with self-esteem $(\mathrm{B}=-0.16, p$ $<.01)$. For every one-point increase in microaggressions, self-esteem is predicted to decrease by 0.16 points. This block accounts for $7 \%$ of the variance in self-esteem scores. In Block 3 , the main effect of microaggressions remains significant $(\mathrm{B}=-0.16, p<.01)$, and the interaction term (gender x microaggressions) does not reach statistical significance.

Microaggressions predicting perceived stress. In Block 2, which accounts for $13 \%$ of the variance of perceived stress, age continues to be a statistically significant predictor of stress $(\mathrm{B}=-0.02, p<.01)$. Microaggressions are positively related to stress $(\mathrm{B}=0.22, p<.001)$. For every one-point increase in microaggressions, stress is predicted to increase by 0.22 points. In the final model, age $(\mathrm{B}=-0.02, p<.01)$ and microaggressions $(\mathrm{B}=0.23, p<.001)$ remain statistically significant predictors of perceived stress. The interaction term (gender $\mathrm{x}$ 
microaggressions) is not significantly related to perceive stress. The final block accounts for $13 \%$ of the variance of perceived stress.

Microaggressions predicting anxiety. In Block 2, microaggressions are positively associated with anxiety $(\mathrm{B}=0.20, p<.001)$ : for each point increase in experiences of microaggressions, one's anxiety score is predicted to increase by 0.20 . This block accounts for $9 \%$ of the variance in anxiety. In Block 3, the main effects of microaggressions remain statistically significant $(\mathrm{B}=0.20, p<.001)$, and the model accounts for $9 \%$ of the variance in anxiety symptoms. The interaction between gender and microaggressions is not statistically significantly associated with anxiety.

\section{Discussion}

The minority stress model maintains that discrimination can increase LGBTQ students' risk for negative outcomes; however, little is known about the role of microaggressions on student's wellbeing. When taking the full sample into account, our results suggest that blatant victimization and microaggressions are each independently associated with lower self-esteem and higher levels of perceived stress and anxiety symptoms. Moreover, we found that gender moderated the relationship between victimization and self-esteem such that trans* students had a more strongly negative association between victimization and self-esteem than cisgender students.

Among the full sample, our results support the minority stress framework. At the bivariate level, significant moderate correlations (not reported) were found between each form of discrimination and each outcome in the anticipated direction; the regression models similarly demonstrated that victimization and microaggressions related to greater forms of psychological distress (lower self-esteem; greater perceived stress and anxiety symptoms). These findings are 
in line with previous research looking at multivariate relationships between victimization and/or microaggressions and well-being (Silverschanz et al., 2008; Woodford et al., 2012; Woodford, Han et al, 2014; Woodford, Kulick et al, 2014). The documented significant positive relationships between microaggressions, self-esteem, perceived stress, and anxiety likely reflect the stressors inherent within microaggressions. That is, although often subtle in nature, microaggressions on campus can increase LGBTQ students' risk for these negative outcomes, just as blatant victimization increases such risks.

Looking at the unstandardized beta coefficients for the models (which can be directly compared since microaggressions and victimization were similarly scaled), victimization had the largest coefficient $(\mathrm{B}=-0.29$ before adding the moderation term) in predicting self-esteem compared to either stress or anxiety ( $\mathrm{B}=0.23$ for both). Microaggressions had a higher coefficient for stress $(B=0.22)$ and anxiety $(B=0.20)$ and the lowest for self-esteem $(B=-$ 0.16). Thus, compared to microaggressions, victimization has a more noticeable relationship with self-esteem, suggesting that blatant insults and threats may have a stronger connection to self-esteem than do microaggressions. Both victimization and microaggressions had similar coefficient results for perceived stress and anxiety symptoms.

The results of the moderation analyses are intriguing. Victimization was significantly negatively associated with self-esteem among cisgender participants, in line with the minority stress model. Further, consistent with this model, victimization was associated with lower selfesteem among trans* students (with a larger coefficient observed compared to that for cisgender students). Experiencing blatant insults and threats may have a particularly impactful presence for trans* students, who past research has suggested experience disproportionate victimization on campus (though the present study did not find a statistical difference between trans* and 
cisgender students in campus victimization). In contract to self-esteem, an interaction between gender and victimization was not significant for stress and anxiety.

It is possible that, for trans* students, the presence of blatant insults and threats may uniquely connect to self-esteem because such insults and threats are added onto the various other forms of microaggressions and discrimination that a trans* student experiences across all sectors of life. In other words, one's self-esteem, which is likely to remain stable despite the daily indignities of microaggressions, is more likely to be influenced by overt acts of violence, threat, and harm that are part of victimization, thus causing one to have lower assessments of one's selfworth. As noted, the difference between cisgender and trans* students was not found for either stress or anxiety as a function of experiences of victimization. Whereas self-esteem represents a fairly steady overall trait characteristic, both perceived stress and anxiety symptoms can fluctuate much more over shorter spans of time, and our results suggest this can occur similarly for trans* and cisgender students.

Gender did not moderate the relationship between microaggressions and any of the forms of psychological distress. Due to the prevalence of microaggressions and other subtle manifestations of discrimination as a more "acceptable" way of expressing prejudice in today's world (Woodford, Han et al., 2014), LGBTQ students, regardless of gender identity, may regularly feel the impact of microaggressions on their self-esteem, stress, and anxiety such that there is no differentiation in these relationships among these subgroups.

\section{Limitations}

The results should be considered in light of the methodological limitations. Given the use of a cross-sectional design, we are unable to determine causation. Though the sample was diverse and large enough for our analysis, it is relatively small, with most participants attending 
schools in the US-Midwest. Additionally, the number of trans* students $(n=72)$ was a small portion of the sample, and results may be different with a larger sample of trans* individuals. The use of convenience sampling prohibits generalizing the findings. Participants were recruited from online LGBTQ networks; students connected to these networks may be more "out" about their sexuality and/or gender identity, more resilient to discrimination, or possess more personal and social resources than others. Use of a racially diverse sample could help with investigating whether there are racial disparities in experiences of LGBTQ victimization microaggressions.

In addition to exploring the explanatory propositions suggested earlier, we recommend that researchers explore the factors that can foster students' resilience to LGBTQ discrimination. We recommend that the role of campus climate programs and policies be explored, as well as both formal and informal supports available to LGBTQ students. Finally, studies are needed to identify the role of peers and instructors in possibly protecting LGBTQ students from the negative effects of victimization and microaggressions. Research in this direction might identify differential effects of initiatives to protect students from victimization and microaggressions.

\section{Implications}

Our findings provide much-needed evidence to inform policy and practice interventions tailored to the needs of LGBTQ college students. Consistent with the Code of Ethics (National Association of Social Workers, 2008), social workers are called to address discrimination both in terms of prevention and treatment. Our results suggest that such efforts need to include both subtle, often minimized, microaggressions, and blatant victimization, especially the latter in fostering strong self-esteem among trans* students. Policies and educational programs need to address both aspects of LGBTQ discrimination if an inclusive and safe environment is to be created for LGBTQ students. For example, ally training programs should prepare participants to 
be able to recognize LGBTQ microaggressions as well as victimization and to effectively intervene in such cases while maintaining personal safety. We believe it will be especially important for student leaders, student affairs staff, and faculty to participate in these programs given that microaggressions can happen anywhere on campus, including residence halls and classrooms.

In clinical settings, our results direct practitioners to inquire about both victimization and microaggressions in order to understand LGBTQ students' well-being. Given that some students may not consider microaggressions to be discrimination, we recommend that practitioners explain the often-subtle nature of contemporary discrimination and give examples. Practitioners may find it beneficial to use the microaggressions scales used in this study to facilitate the assessment process. Social work schools and professional development programs should address microaggressions in their programs (see Keuroghlian, Shtasel, \& Bassuk, 2014). Moreover, practitioners need to assess LGBTQ students' coping skills and resilience factors. Further, when lacking, practitioners need to advocate for programs and services that specifically support LGBTQ students. 


\section{References}

Case, K. A., Kanenberg, H., Erich, S., \& Tittsworth, J. (2012). Transgender inclusion in university nondiscrimination statements: Challenging gender-conforming privilege through student activism. Journal of Social Issues, 68(1), 145-161. doi:10.1111/j.15404560.2011.01741.x

Cohen, S., Kamarck, T., \& Mermelstein, R. (1983). A global measure of perceived stress. Journal of Health and Social Behavior, 24, 385-396. doi:10.2307/2136404

D’Augelli, A. R. (1992). Lesbian and gay male undergraduates' experiences of harassment and fear on campus. Journal of Interpersonal Violence, 7, 383-395. doi:10.1177/088626092007003007

Dugan, J. P., Kusel, M. L., \& Simounet, D. M. (2012). Transgender college students: An exploratory study of perceptions, engagement, and educational outcomes. Journal of College Student Development, 53(5), 719-736. doi:10.1353/csd.2012.0067

Effrig, J. C., Bieschke, K. J., \& Locke, B. D. (2011). Examining victimization and psychological distress in transgender college students. Journal of College Counseling, 14(2), 143-157. doi:10.1002/j.2161-1882.2011.tb00269.x

Hendricks, M. L., \& Testa, R. J. (2012). A conceptual framework for clinical work with transgender and gender nonconforming clients: An adaptation of the Minority Stress Model. Professional Psychology: Research and Practice, 43(5), 460-467. doi:10.1037/a0029597

Herek, G. M. (1993). Documenting prejudice against lesbians and gay men on campus: The Yale sexual orientation survey. Journal of Homosexuality, 25, 15-30. doi: 10.1300/ J082v25n04_02 
Herman, J. L. (2013). Gendered restrooms and minority stress: The public regulation of gender and its impact on transgender people's lives. Journal of Public Management \& Social Policy, 65-80.

Keuroghlian, A. S., Shtasel, D., \& Bassuk, E. L. (2014). Out on the street: A public health and policy agenda for lesbian, gay, bisexual, and transgender youth who are homeless. American Journal of Orthopsychiatry, 84(1), 66-72. doi:10.1037/h0098852

Meyer, I. H. (2003). Prejudice, social stress, and mental health in lesbian, gay, and bisexual populations: conceptual issues and research evidence. Psychological Bulletin, 129(5), 674-97. doi:10.1037/0033-2909.129.5.674

Nadal, K. L. (2013). Gender identity microaggressions: Experiences of transgender and gender nonconforming people. In That's so gay! Microaggressions and the lesbian, gay, bisexual, and transgender community (pp. 81-107). Washington, D.C.: American Psychological Association.

Nadal, K. L., Rivera, D. P., \& Corpus, M. J. H. (2010). Sexual orientation and transgender microaggressions: Implications for mental health and counseling. In D. W. Sue (Ed.), Microaggressions and marginality: Manifestation, dynamics, and impact (pp. 217-240). Hoboken, NJ: John Wiley \& Sons, Inc.

National Association of Social Workers (NASW). (2008). Code of ethics of the National Association of Social Workers. Retrieved from http://www.socialworkers.org/pubs/ code/code.asp

Nicolazzo, Z. (2015). “Just go in looking good”: The resilience, resistance, and kinship-building of trans* college students (Doctoral dissertation). Retrieved from http://www.ohiolink.edu/etd/ 
Rankin, S., Weber, G., Blumenfeld, W., \& Frazer, S. (2010). 2010 State of higher education for lesbian, gay, bisexual \& transgender people. Charlotte, NC.

Rosenberg, M. (1965). Society and the adolescent self-image. Princeton, NJ: Princeton University Press.

Rosenberg, M., Schooler, C., Schoenbach, C., \& Rosenberg, F. (1995). Global self-esteem and specific self-esteem: Different concepts, different outcomes. American Sociological Review, 60, 141-156. doi: 10.2307/2096350

Seelman, K. L. (2013). A mixed methods examination of structural bigenderism and the consequences for transgender and gender variant people. Retrieved from ProQuest Dissertations and Theses Database. (UMI No. 3588397).

Seelman, K. L. (2016). Transgender adults' access to college bathrooms and housing and the relationship to suicidality. Journal of Homosexuality. Advance online publication. doi: $10.1080 / 00918369.2016 .1157998$

Silverschanz, P., Cortina, L. M., Kornik, J., \& Magley, V. J. (2008). Slurs, snubs, and queer jokes: Incidence and impact of heterosexist harassment in academia. Sex Roles, 58, $179-$ 191. doi:10.1007/s11199-007-9329-7

Spitzer, R. L., Kroenke, K., Williams, J. B., \& Löwe, B. (2006). A brief measure for assessing generalized anxiety disorder: The GAD-7. Archives of Internal Medicine, 166, 10921097. doi:10.1001/archinte.166.10.1092

Tabachnick, B. G., \& Fidell, L. S. (2007). Using multivariate statistics (5th ed.). Boston, MA: Pearson Education. 
Trzesniewski, K. H., Donnellan, M. B., \& Robins, R. W. (2003). Stability of self-esteem across the life span. Journal of Personality and Social Psychology, 84, 205-220. doi:10.1037/0022-3514.84.1.205

Woodford, M. R., Chonody, J. M., Kulick, A., Brennan, D. J., \& Renn, K. (2015). The LGBQ microaggressions on campus scale: A scale development and validation study. Journal of homosexuality, 62(12), 1660-1687. doi: 10.1080/00918369.2015.1078205

Woodford, M. R., Han, Y., Craig, S., Lim, C., \& Matney, M. M. (2014). Discrimination and mental health among sexual minority college students: The type and form of discrimination does matter. Journal of Gay \& Lesbian Mental Health, 18(2), 142-163. doi: $10.1080 / 19359705.2013 .833882$

Woodford, M. R., Howell, M. L., Silverschanz, P., \& Yu, L. (2012). “That's so gay!”: Examining the covariates of hearing this expression among gay, lesbian, and bisexual students. Journal of American College Health, 60(6), 429-434. doi:

$10.1080 / 07448481.2012 .673519$

Woodford, M. R., Kulick, A., Sinco, B. R., \& Hong, J. S. (2014). Contemporary heterosexism on campus and psychological distress among LGBQ students: The mediating role of selfacceptance. American Journal of Orthopsychiatry, 84(5), 519-529. doi: 10.1037/ort0000015 


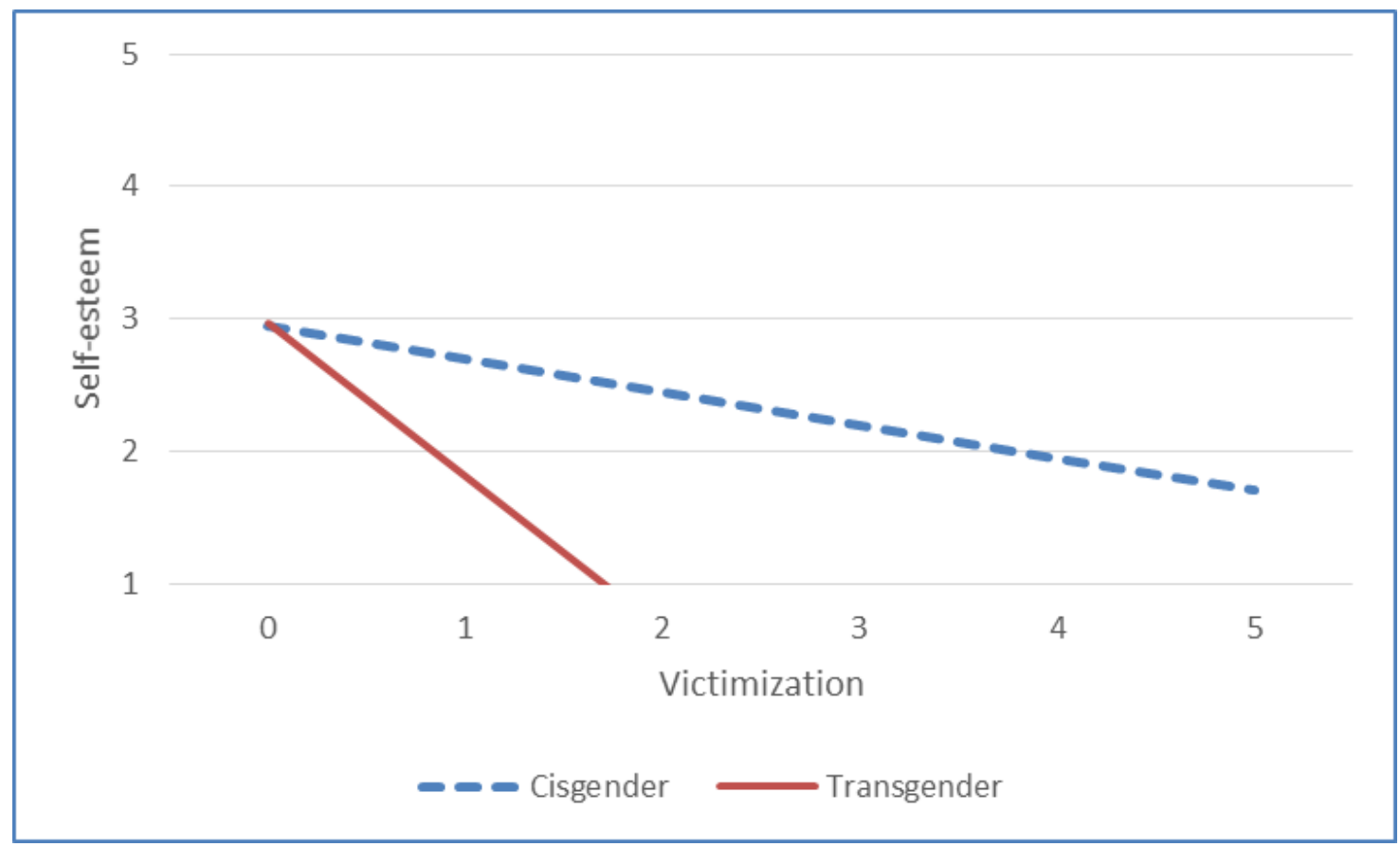

Figure 1. Gender's moderation of the relationship between blatant victimization and self-esteem. 